\title{
Cuba y el sistema interamericano. \\ Entre el mito político y la realidad jurídica
}

\author{
Cuba and the Inter-American System. \\ Among the political myth and the legal \\ reality
}

\author{
Raudiel Francisco Peña Barrios \\ Estudiante de Maestría en Ciencias \\ Políticas de El Colegio de México \\ (COLMEX)
}

\section{Resumen}

Se analizará el vínculo jurídico de la República de Cuba con el sistema interamericano, en particular con el Sistema Interamericano de Derecho Humanos (SIDH), al amparo del Derecho Internacional. Con tal propósito, se realizará un estudio histórico-jurídico sobre el origen del sistema interamericano y las relaciones de Cuba con este, previo a 1959. Se procederá a dilucidar cuál es el estatus jurídico que Cuba conserva respecto a dicho sistema, con posterioridad a que se interrumpieran sus relaciones con la Organización de Estados Americanos (OEA), en 1962. Por último, se expondrá la actualidad de los nexos jurídicos que aún existen entre el sistema interamericano y el Estado cubano, y algunas reflexiones sobre su posible integración plena en el mentado sistema.

Palabras claves: Cuba, OEA, sistema interamericano, integración regional, derechos humanos.

\section{Abstract}

Will analyze the legal link of the Republic of Cuba with the inter-American system, in particular with the InterAmerican System of Human Rights (ISHR), under the protection of International Law. With this purpose, will be carried out a historical-legal analysis on the origin of the inter-American system and Cuba's relations with it, prior to 1959. Will proceed to elucidate the legal status that Cuba maintains with respect to said system, with after its relations with the Organization of American States (OAS) were interrupted in 1962. Lastly, the current status of the legal ties that still exist between the inter-American system and the Cuban State will be exposed, and some reflections on their possible full integration in the mentioned system.

Keywords: Cuba, OAE, interamerican system, regional integration, human rights.

\section{Introducción}

El sistema interamericano es uno de los grandes sistemas políticos regionales que coexisten junto al sistema internacional general, con un enfoque importante en la integración y en la promoción, tutela y defensa de los derechos humanos. La lógica sobre la cual descansa la existencia de estos, es que a lo interno de los mismos puede verificarse una mayor homogeneidad política, económico, social, cultural y jurídica entre los países que los integran, que con respecto al Sistema Universal de Derechos Humanos que tiene como centro a la Organización de las Naciones Unidas (ONU). La República de Cuba, nación fundadora de esta última organización en 1945 y que ratificó la Carta de la Organización de Estados Americanos (OEA) el 8 de julio de 1952, tiene una larga historia de inserción en el concierto internacional de naciones que comprendieron que la integración entre iguales traería, entre otros beneficios, la determinación de estándares mínimos en derechos humanos (Arellano, 1983, p. 631; y Departamento de Derecho Internacional de la Secretaría General de la OEA, 2020).

Para los efectos de este trabajo, se asumirá como el punto de inicio del desarrollo del sistema interamericano la Primera Conferencia Internacional Americana celebrada en Washington D.C., Estados Unidos, entre 1889 y 1890 . Hay por supuesto, y desde mucho antes, antecedentes de esfuerzos regionales de creación de normas y de instituciones, pero es a partir de esta Conferencia que el trabajo conjunto se haría sistemático e incesante hasta nuestros días, asumiéndose desde ese entonces como necesario la creación de una organización continental. Valórese que según Sierra, fue a partir de este momento que se pensó la creación de una Oficina de Repúblicas Americanas con una función centralizadora informativa bajo la dirección de un acuerdo integrado con todas las repúblicas americanas (Sierra, 1955, p. 229). 
De estas conferencias surge un importante marco normativo y un rico tejido institucional (Arrighi, 2009, p. 70). Con base en este entorno, que se manifiesta en el orden de los instrumentos jurídicos y el de las instituciones políticas y de otra tipología, es que puede estudiarse el sistema interamericano desde el Derecho Internacional. Ese es el propósito central de este artículo: analizar el estatus jurídico de Cuba con respecto al mismo, evaluando las problemáticas de esta relación, pero al mismo tiempo desmitificando el discurso político que obvia el componente jurídico de este vínculo, hasta hoy no disuelto.

En tal sentido, se ha vertebrado este trabajo en seis partes. En el segundo epígrafe se estudiará el origen del sistema interamericano a partir de la creación de la OEA en 1948 y la situación de Cuba en esos primeros años, hasta 1959. A continuación, se analizará la ruptura política, pero no jurídica, de Cuba con la OEA y toda la estructura institucional creada en torno a esta organización, poniendo especial énfasis en las relaciones de este país con la Comisión Interamericana de Derechos Humanos (CIDH-Comisión). De igual manera, abordaremos el cambio de postura política que supuso la resolución adoptada en 2009 por la Asamblea General de la OEA sobre el estatus jurídico de Cuba, así como la posición del Estado cubano al respecto. Por último, expondremos algunas consideraciones para argumentar, desde la perspectiva del Derecho Internacional y según el contenido de la Constitución cubana de 2019, si es factible para Cuba lograr su plena reinserción en el sistema regional.

\section{El origen del sistema interamericano y la inserción de Cuba (1948-1959)}

De conformidad con Arrighi, en las primeras décadas del siglo XX se fueron constituyendo varias entidades e instituciones que son la génesis del actual sistema interamericano. Así surgieron el Comité Jurídico Interamericano, la Organización Panamericana de la Salud (OPS), la Comisión Interamericana de Mujeres, el Instituto Interamericano del Niño, la Unión Panamericana, entre otros. En 1948, la Octava Conferencia aprueba la creación de la OEA, aunque seguirían creándose nuevas instancias, organismos y entidades comunes, algunos como órganos de la propia OEA - por ejemplo la Comisión Interamericana de Derechos Humanos, la Comisión Interamericana de Telecomunicaciones, la Comisión Interamericana para el Control del Abuso de Drogas- y otros emanados de acuerdos adopta- dos en el seno de esta organización, como son los casos de la Corte Interamericana de Derechos Humanos (CIDH-Corte) y el Banco Interamericano de Desarrollo (BID) (Arrighi, 2009, p. 71).

Además de las instituciones y entidades mencionadas, hoy en día el sistema interamericano se presenta, desde la perspectiva orgánica, como un conjunto de organizaciones heterogéneas en cuanto a su tipología. Comprende organizaciones multilaterales como la OEA o el BID; organismos y entidades varias -Junta Interamericana de Defensa (JID); Instituto Interamericano de Cooperación para la Agricultura (IICA) - entre otros. Asimismo, existen entidades técnicas, resaltando la Comisión Interamericana para el Control del Abuso de Drogas (CICAD); el Comité Interamericano contra el Terrorismo (CICTE) y la Comisión Interamericana de Mujeres (CIM), entre otras. A la par, están incluidos foros intergubernamentales como las Reuniones de Ministros (Justicia, Trabajo, Seguridad Pública, Educación, Mujer, etc.), las Conferencias Especializadas y las Cumbres de las Américas con el Grupo de Implementación de Cumbres (GRIC) (Ramacciotti, 2016, p. 337). Todo este entramado institucional ha dado lugar a un sistema internacional de alcance regional, cuyos elementos integrantes tienen diferentes tipos de relación con la OEA.

Esta última es una organización internacional debido a que se constituyó sobre asociaciones voluntarias de pactadas por acuerdo internacional, está dotada de órganos permanentes, propios e independientes, encargados de gestionar intereses colectivos y capaces de expresar una voluntad jurídicamente distinta de la de sus miembros. La vocación de este organismo interamericano estriba en favorecer la cooperación interna de los Estados que lo componen y en confrontar los problemas que le son comunes. Esta definición entraña los cuatro caracteres esenciales que singularizan a cualquier organización internacional respecto al Estado como sujeto por excelencia del Derecho Internacional, a saber: composición en esencia interestatal, base jurídica que por regla general es convencional, una estructura orgánica permanente e independiente y autonomía jurídica (Diez de Velazco, 2002, p. 44). En el caso particular de la OEA se trata de una organización de alcance continental, por lo que según Cuevas el sistema interamericano ofrece las delicadas y criticables características del provincialismo. Su vocación se reduce a resolver los problemas internos del continente (1968, p. 408). 
En paralelo, desde la óptica normativa se ha producido un copioso marco legal elaborado con contenidos tanto del Derecho Internacional Público como Privado. Convenciones sobre Derechos y Deberes de los Estados, sobre Solución Pacífica de las Controversias, fomento del comercio, la codificación del derecho internacional privado, arbitraje, normas sobre reservas a los tratados, Derecho del mar, uso de recursos compartidos, etcétera, fueron luego fuente de inspiración del proceso codificador universal. Desde la perspectiva jurídica, las declaraciones, resoluciones, convenciones y tratados aprobados desde fines del siglo diecinueve hasta la fecha, conforman el denominado Derecho Interamericano, que constituye el armazón legal supranacional que se aplica a nivel continental, en forma complementaria y dentro del marco del Derecho Internacional general (Arrighi, 2015, p. 24).

De igual forma, téngase presente que los Estados parte del sistema interamericano llegaron con todo este patrimonio al seno de las Naciones Unidas, cuando esta se creó en 1945. Allí formaban un grupo que totalizaba casi un cuarenta por ciento de los miembros de su Asamblea General, con una fuerte presencia en todas las demás instancias y órganos de la nueva organización universal. Esto repercutió, junto a otros factores, para que en la Carta de la ONU, artículos del 52 al 54, se prevenga la existencia de acuerdos u organismos regionales, siempre que estos y sus actividades sean compatibles con los propósitos y principios de las Naciones Unidas. Con el concepto de acuerdos y organismos regionales se entienden tanto las organizaciones internacionales en sentido estricto como las formas más flexibles de la asociación de Estados, que aún no han llegado a una consolidación organizacional de los vínculos estatales (p. ej. la Organización para la Cooperación y la Seguridad Europea). La renuncia a una disposición conceptual adicional tiene por objeto permitir la vinculación lo más amplia posible de las organizaciones regionales y de otras formas de la cooperación regional. Las organizaciones clásicas en el sentido del artículo 52, numeral 1, de la Carta de la ONU son el Consejo de Europa, la OEA y la actual Unión Africana (Herdegen, 2015, p. 337; y Arellano, 1983, p. 501). A la vez, el vínculo con la ONU influyó en que el sistema interamericano se sostenga sobre dos pilares que son complementos entre sí, y que forman parte de la base axiológica sistema internacional general: la igualdad jurídica de los Estados y el principio de no intervención (Arrighi, 2009, p. 72).
En el propio año 1948, Cuba aprobó la Carta constitutiva de la OEA como miembro fundador, la cual ratificaría cuatro años más tarde, adhiriéndose a principios tales como la igualdad jurídica de los Estados y la no intervención en los asuntos internos; y que, al mismo tiempo, acepta que la solidaridad de los Estados Americanos requiere la organización política de los mismos sobre la base del ejercicio efectivo de la democracia representativa. El país también suscribió la Declaración Americana de los Derechos y Deberes del Hombre, que incorpora, entre otros, el derecho al sufragio universal y a participar en elecciones populares, genuinas, periódicas y libres (Ramacciotti, 2016, p. 339). De tal forma, la República de Cuba mostró vocación de asumir obligaciones internacionales tanto en el marco universal como interamericano, priorizándose el primero por sobre el segundo luego de la interrupción de las relaciones del país con la OEA, en los años sesenta. Evidencia de esto es el interés político del Estado cubano por pertenecer a organismos especializados en derechos humanos en el marco de la ONU, lo que se constata con su reciente elección como miembro del Consejo de Derechos Humanos, hasta 2023 (Cubadebate, 2020).

\section{Ruptura y propuesta de reconciliación. Las relaciones de Cuba con el sistema interamericano (1959-actualidad)}

Con lo explicitado hasta aquí, vale preguntarse cuál es el estatus jurídico de Cuba respecto al sistema interamericano. De igual forma, hay que tener en cuenta cuáles son las posiciones de este país y de la OEA, dado que esta última es el centro del mismo, sobre la plena incorporación del Estado cubano a dicho sistema. Como se verá, en el fondo de este asunto subyacen más razones políticas radicales que jurídicas.

Una primera cuestión que es propicio aclarar, es que Cuba no fue expulsada de la OEA, ni se fue de la OEA, ni necesita solicitar su reingreso a la misma. Tal y como ya se expuso el Estado cubano es un miembro fundador de esta organización internacional y nunca denunció su Carta constitutiva, derecho que podía haber ejercido de acuerdo con lo que dispone el artículo 143 actual (Arrighi, 2009, p. 75). En segundo orden, debe considerarse que, al menos en un primer momento, el gobierno cubano que se instaló en el poder en 1959 como consecuencia de un movimiento insurreccional armado, no renunció al marco jurídico interamericano ni a su 
participación en las instituciones políticas y de otro tipo que lo conformaban.

En el propio año 1959, en la V Reunión de Consulta de Ministros de Relaciones Exteriores de la OEA realizada en Santiago de Chile, Cuba aprobó la resolución por la que se creó la Comisión Interamericana de Derechos Humanos, órgano del sistema interamericano encargado de la promoción, tutela y defensa de los derechos humanos en los países miembros de la OEA, de conformidad con los estándares universales e interamericanos (Ramacciotti, 2016, p. 339). El país seguiría participando en estas reuniones y otros espacios de concertación, hasta 1962 (LeoGrande y Kornbluh, 2015, p. 75).

En ese año, el gobierno de Cuba fue excluido de su participación del sistema interamericano en su totalidad y no solo de la OEA por aplicación del Tratado Interamericano de Asistencia Recíproca (TIAR), acordando la VIII Reunión de Ministros de Relaciones Exteriores (Punta del Este, Uruguay) convocada en el marco del mismo, que su adhesión al marxismo-leninismo era una amenaza a la paz continental. Cuba participó es esa reunión y fue el único país que votó en contra de esta decisión (Arrighi, 2009, p. 75). De los Estados que en ese momento ostentaban la condición de parte en el TIAR catorce votaron por la afirmativa, seis se abstuvieron y uno votó en contra. Halajczuk y Moya plantean que esta medida fue aplicada a Cuba por una doble infracción de naturaleza interna y externa, la eliminación de un orden interno obligatorio, la democracia, y la deserción hacia el campo enemigo, o sea, al marxismo (1999, p. 202).

Dos años más tarde, el 26 de julio de 1964, durante una reunión de cancilleres y de nuevo en aplicación del TIAR, se condenaron actos de intervención y de agresión del gobierno de Cuba contra Venezuela, miembro de la OEA y Estado Parte en el TIAR. Este país presentó una solicitud formal y se resolvió solicitar a los Estados americanos la interrupción de sus relaciones bilaterales con Cuba (Gleijeses, 2004, pp. 41, 42 y 75). Esta nueva resolución fue aprobada por dieciséis votos a favor y cuatro en contra. Su legalidad fue muy debatida y algunos Estados se negaron a cumplirla, dadas las agresivas presiones de Estados Unidos para que se formulara una enérgica condena a las acciones de Cuba y se impusieran sanciones regionales. Los cuatro países que votaron en contra fueron Bolivia, Chile, México y Uruguay, pero solo México se negó a acatar el rompimiento de relaciones con Cuba (LeoGrande y Kornbluh, 2015, pp. 131-133). En 1975 esta segunda sanción fue le- vantada y se quebró cualquier vínculo jurídico que prohibiera a los Estados miembros de la OEA tener relaciones bilaterales con Cuba, en la forma que les resultara conveniente (Arrighi, 2009, p. 76).

A partir de este momento, y de acuerdo con Pisani, se insistió por parte de varios Estados latinoamericanos y caribeños en el reexamen del caso cubano en la OEA y algunos países promovieron diversas iniciativas en tal sentido. Fidel Castro las calificó como un objetivo positivo, ya que constituían un desacato, un gesto de rebeldía frente a la influencia de Estado Unidos en esa organización. El jefe de Estado y de Gobierno cubano indicó que Cuba no era contraria a la creación de una organización regional que comprendiera a los países latinoamericanos y a los de habla inglesa del Caribe, siempre que Estados Unidos no estuviera incluido en esa organización (Pisani, 1985, p. 572). El carácter problemático de las relaciones Cuba-OEA luego de 1959, guarda estrecha relación con el entorno de Guerra Fría que primaba en el mundo y el recrudecimiento del diferendo histórico entre Cuba y Estados Unidos. No obstante, en medio de este contexto la mayoría de las naciones del continente establecieron relaciones con Cuba en diversas áreas, lo que demostró que era posible la coexistencia pacífica entre iguales, aun teniendo profundas diferencias políticas e ideológicas. Esto último puede estimarse como una anticipación al surgimiento de la Comunidad de Estados Latinoamericanos y Caribeños (CELAC), en el año 2010.

Pues entonces la situación del gobierno de Cuba con relación a la OEA hasta junio de 2009 era esta: Estado miembro de la misma con su gobierno suspendido de la participación en sus actividades y en lo bilateral relaciones diplomáticas, comerciales, consulares o de otro tipo con la casi totalidad de los demás miembros de esta organización. La Asamblea General de la OEA en su período ordinario de sesiones de 2009, celebrado en San Pedro Sula (Honduras), aprobó por consenso la Resolución AG/RES. $\mathrm{N}^{\circ} 2438$ (XXXIX-O/o9) dejándose sin efecto la resolución de 1962 que suspendiera al gobierno de Cuba (Arrighi, 2009, p. 76). Un factor sin dudas trascendente para adoptar tal decisión, fue la existencia en ese momento de un entorno geopolítico a nivel regional caracterizado por la presencia en el poder de varios gobiernos de izquierda, unos más radicales que otros, en países como Argentina, Bolivia, Brasil, Nicaragua, Uruguay y Venezuela.

Otro momento importante en las relaciones Cuba-OEA ocurrió en abril de 2015, cuando por 
primera vez este país participó en la Cumbre de las Américas, efectuada en Panamá (LeoGrande y Kornbluh, 2015, pp. 494-499). Ello en medio de un contexto signado por el proceso de restablecimiento y normalización de relaciones entre Cuba y Estados Unidos, muy dañado por la llegada al poder de la administración Trump, en 2016. La presencia de una delegación de alto nivel, encabezada por Raúl Castro, fue indicativa del interés político del Estado cubano por participar en ese espacio multilateral. A esto habría que agregar el ingreso de Cuba como miembro pleno al Banco Centroamericano de Integración Económica, lo cual supone una evaluación positiva sobre la utilidad de esta institución financiera multilateral en el marco hemisférico, aunque la misma esté fuera de la órbita de la OEA o del sistema interamericano en su conjunto (Diario Granma, 2017).

Debemos aclarar que la Resolución AG/RES. No2438 (XXXIX-O/o9) no involucra ningún tipo de condicionamiento explícito en el plano jurídico para el Estado cubano, entendiendo que no se supedita su incorporación al sistema interamericano a la reforma de su sistema político y/o de su ordenamiento jurídico, ni se evidencian cuestionamientos a la ideología oficial del mismo (Guanche, 2015, pp. 49-52). Solo se subraya que para la participación de Cuba en la OEA debe mediar la solicitud de diálogo por parte de su gobierno y la voluntad de adherirse a las prácticas, los propósitos y principios fundamentales que ha defendido la OEA, relacionados con la seguridad, la democracia, la autodeterminación, la no intervención, los derechos humanos y el desarrollo (Preciado y González, 2011, p. 63).

Correspondería al Consejo Permanente dialogar con el gobierno cubano, cuando así este lo estime pertinente, puesto que la Carta dispone que cuando el cumplimiento de un mandato de la Asamblea General no haya sido encomendado a ninguna otra instancia, corresponde al Consejo Permanente ejecutarlo (artículo 91 inciso a)). Al día de hoy este diálogo no se ha iniciado (Arrighi, 2009, p. 76). Respecto al TIAR, Cuba y otros países miembros de la Alianza Bolivariana para los Pueblos de América-Tratado de Cooperación de los Pueblos (ALBA-TCP) anunciaron en 2012 que lo denunciarían, pero este procedimiento aún no se ha oficializado (Ramacciotti, 2016, p. 339).

Esta forma de dar por terminadas las obligaciones contraídas por un Estado respecto a un tratado internacional, que también se conoce como retiro y que aplica tanto en tratados bilaterales como mul- tilaterales, puede definirse como el acto por el cual uno de los Estados contratantes notifica al resto de su intención de dar por terminado el tratado, puesto que se ha vuelto inoperante en la relaciones entre ellos, ya sea a partir de la fecha de la declaración o de otra (Pisani, 1985, p. 86). En efecto, se trata de un acto unilateral del Estado por el que se hace del conocimiento de los otros Estados parte, su intención de no continuar asociado al tratado. Se ha planteado que la denuncia se refiere a los tratados bilaterales, mientras que el retiro alude a un tratado multilateral. Sin embargo, esto no es preciso, puesto que los tratados multilaterales llegan a utilizar el término denuncia y no retiro (Becerra y Ávalos, 2020, p. 156).

Para su operatividad debe tratarse de un supuesto en que el tratado o las obligaciones dimanantes de él han entrado en crisis. La gravedad que una situación tal encierra, antítesis de la norma pacta sunt servanda, hizo que al codificarse el Derecho de Tratados se hayan puesto una serie de trabas para disminuir, en la medida de lo posible, los efectos que la nulidad, anulabilidad, terminación y suspensión puedan acarrear. Las referidas limitaciones abarcan, entre otras -artículos del 42 al 45 de la Convención de Viena sobre Derecho de Tratados- que la validez de un tratado o el consentimiento prestado al mismo solo puedan impugnarse sobre la base este instrumento jurídico, y que la terminación, denuncia, retirada o suspensión de un tratado solo pueda hacerse en aplicación de las normas del propio tratado o de la citada convención (Diez de Velazco, 2013, p. 218).

El segundo de estos supuestos se aplica a la Carta de la OEA y el TIAR, debido a que en ambos se pautan condiciones específicas para que los Estados puedan desligarse de las obligaciones contraídas, en virtud de su adhesión a ambos tratados (Arrighi, 2009, pp. 74 y 75). En el artículo 143 del primero de estos instrumentos jurídicos se preceptúa que esta Carta regirá indefinidamente, pero podrá ser denunciada por cualquiera de los Estados miembros, mediante comunicación escrita a la Secretaría General, la cual comunicará en cada caso a los demás las notificaciones de denuncia que reciba. Transcurridos dos años a partir de la fecha en que la Secretaría General reciba una notificación de denuncia, la presente Carta cesará en sus efectos respecto del Estado denunciante, y éste quedará desligado de la Organización después de haber cumplido con las obligaciones emanadas de la presente Carta (Organización de Estados Americanos, 2020). Por su parte, en el artículo 25 del TIAR se indica que este regirá de manera indefinida, pero las obligaciones contraídas pueden 
darse por terminadas si es denunciado por cualquier de las Altas Partes Contratantes, mediante la notificación escrita de la Unión Panamericana, la cual comunicará a todas las otras Altas Partes Contratantes cada una de las notificaciones de denuncia que reciba. Transcurridos dos años a partir de la fecha de que la Unión Panamericana reciba una notificación de denuncia de cualquiera de las Altas Partes Contratantes, el presente Tratado cesará en sus efectos respecto a dicho Estado, quedando subsistente para todas las demás Altas Partes Contratantes (Organización de Estados Americanos, 2020).

Los casos de la Carta de la OEA y del TIAR demuestran que en el sistema interamericano la tendencia es que la denuncia, retirada o suspensión de un tratado se efectúa por la aplicación de las normas del mismo. Si bien los textos elaborados dentro del mentado sistema parten de la premisa que "rigen indefinidamente", la mayoría de ellos contienen estipulaciones que se pronuncian sobre la salida de un tratado e imponen como principal condición de fondo el consentimiento del Estado interesado, en concordancia con la doctrina que asume el consentimiento de los Estados como la piedra angular que gobierna el diseño y el funcionamiento de las cláusulas de salida (Toro, 2019, p. 83). Cabe recordar que Cuba es Estado Parte de la Convención de Viena sobre Derecho de Tratados de 1969. Los Estados miembros de la OEA que no son partes en dicha convención son: Antigua y Barbuda, Bolivia (firmó), Belice, Dominica, El Salvador (firmó), Granada, Nicaragua, San Cristóbal y Nieves, Saint Lucia, Bahamas, Trinidad y Tobago (firmó), Estados Unidos (firmó) y Venezuela (Toro, 2019, nota 7, p. 111).

A día de hoy existen dos grandes excepciones respecto a la participación de Cuba en el sistema interamericano. Una de ellas es su presencia en la OPS, que constituye a la vez un organismo especializado de la OEA y de la Oficina Regional de la Organización Mundial de la Salud (OMS). Cuba, en su calidad de Estado miembro de Naciones Unidas, pudo conservar su sitio en la OPS. La otra excepción es la competencia que ejerce la CIDH-Comisión sobre la situación de los derechos humanos en Cuba, que aparece reflejada en análisis y recomendaciones contenidas en informes especiales y/o en los informes anuales que se presentan ante la Asamblea General de la OEA (Ramacciotti, 2016, p. 340)

La CIDH-Comisión, órgano cuya creación y competencia está previstos en el artículo 106 de la Carta de la OEA, es parte de lo que en la doctrina se conoce como Sistema Interamericano de Derechos Humanos, el cual podría definirse, de manera sucinta, como un subsistema dentro del conjunto de instituciones e instrumentos jurídicos interamericanos, orientado al Derecho Internacional de los Derechos Humanos. Forma parte integrante de uno de los tres grandes sistemas regionales que existen en el mundo, junto con el europeo y el africano (Diez de Velazco, 2013, p. 697). En el marco de los mismos, junto a los sistemas universales de control desarrollados en torno a la ONU, han hecho su aparición importantes sistemas regionales de protección de los derechos humanos que se despliegan, como regla, en el seno de las grandes organizaciones regionales de fines generales. Se trata de un fenómeno en proceso expansivo que se proyecta sobre todos los ámbitos regionales. El Sistema Interamericano de Derechos Humanos se enfoca en la promoción, tutela y defensa de los derechos humanos en la región y es un elemento fundamental en el análisis de la situación de esta temática en cualquier Estado miembro de la OEA. Se trata de una actividad relacionada con su competencia genérica para realizar estudios en el ámbito de los derechos humanos (O’Donnell, 1989, pp. 511-530).

Su corpus iuris está conformado por la Declaración Americana de los Deberes y Derechos del Hombre (1948), la Carta Interamericana de Garantías Sociales (1948) (Unión Panamericana, 1956, pp. 195203), la Convención Americana sobre Derechos Humanos (Pacto de San José, 1969), las convenciones sobre tortura, violencia contra la mujer, desaparición forzada de personas, discriminación contra las personas con discapacidad, así como el Protocolo a la Convención Americana sobre Derechos Humanos relativo a la abolición de la Pena de Muerte y el Protocolo Adicional a la Convención Americana sobre Derechos Humanos en materia de Derechos Económicos, Sociales y Culturales (Protocolo de San Salvador, 1988) (Quintana, 2006, p. 150; y Carbonell et al., 2002). Estos tratados son parte del conjunto de instrumentos jurídicos sobre derechos humanos, pues la relación de los mismos no es exhaustiva.

Con la adopción del segundo de los protocolos mencionados se hizo posible la inclusión de un grupo de derechos de esta tipología dentro del sistema interamericano, porque la Convención Americana solo alude a derechos civiles y políticos. Con el devenir del tiempo y como parte de un proceso lógico de consolidación de su trabajo, y dadas las complejidades continentales en torno a los derechos humanos, la CIDH-Comisión, que surgió como un órgano de consulta, ha ido transmutándose hasta convertirse en 
un órgano de control, sin perder su esencia consultiva, junto con la CIDH-Corte. Ambos son órganos permanentes de la OEA con autonomía funcional y el segundo es de tipo jurisdiccional en sentido estricto (Quintana, 2006; y Diez de Velazco, 2013, p. 715). Precisar que la diferencia fundamental entre esta última organización y la CIDH-Comisión está dada por la tipología y los mandatos o propósitos de ambas. Mientras que la OEA es una organización internacional enfocada en las relaciones interestatales (artículos 1 y 2 de la Carta de la OEA), la CIDH-Comisión es un órgano de control y consulta, mandatado para la protección y promoción de los derechos humanos en el continente (Pelayo, 2011, pp. 10-44; Ledesma, 2004; Comisión Nacional de los Derechos Humanos, 2018, pp. 11-13).

Como se planteó con anterioridad, Cuba participó en la V Reunión de Consulta de Ministros de Relaciones Exteriores de la OEA -efectuada en Santiago de Chile, en 1959- donde se determinó, mediante una resolución, crear la CIDH-Comisión. En este espacio de concertación política, el gobierno revolucionario cubano emitió su voto favorable para que surgiera este órgano, de manera tal que aceptó su incorporación en la estructura orgánica del sistema interamericano reconociendo, de iure, su competencia en lo que a derechos humanos respecta. Tal acción legitima, al amparo del Derecho Internacional e Interamericano, y más allá de que las autoridades cubanas no reconozcan desde el punto de vista político la legitimidad de los pronunciamientos de los organismos regionales, la emisión por parte de la CIDH-Comisión de informes generales o temáticos sobre la situación de los derechos humanos en Cuba, y el tratamiento de esta cuestión en los informes que cada año elabora este órgano para ser presentados ante la Asamblea General de la OEA (Comisión Interamericana de Derechos Humanos, 2018 y 2020).

El principal instrumento jurídico internacional que sirve de fondo para la emisión de estos informes es la Declaración Interamericana de Derechos Humanos, con la cual Cuba se vinculó al momento de suscribir la Carta de la OEA. Además, respecto a los Estados que no han ratificado la Convención Americana sobre Derechos Humanos, como es el caso cubano, los Estados le confirieron a dicha comisión la facultad de prestar particular atención a la tarea de la observancia de los derechos humanos mencionados en los artículos I, II, III, IV, XVIII, XXV y XXVI de la Declaración Americana de los Derechos y Deberes del Hombre, según lo dispone el artículo 20(a) del Estatuto de la CIDH (Comisión Interamericana de Derechos Humanos, 2020, p. 9).

Sobre la naturaleza jurídica de la antedicha declaración es oportuno señalar que, en virtud de la Opinión Consultiva OC-10/89 de 14 de julio de 1989 emitida por la CIDH-Corte, la circunstancia de que la misma no sea un tratado no implica que carezca de efectos jurídicos. Por ende, el artículo 64.1 de la Convención Americana sobre Derechos Humanos autoriza a la Corte para, a solicitud de un Estado Miembro de la OEA o, en lo que les compete, de uno de los órganos de la misma, rendir opiniones consultivas sobre la interpretación de la Declaración Americana de los Derechos y Deberes del Hombre, en el marco y dentro de los límites de su competencia en relación con la Carta y la Convención u otros tratados concernientes a la protección de los derechos humanos en el ámbito continental. En el caso cubano, y en virtud de tal pronunciamiento, el Estado debe proteger y garantizar los derechos postivados en la Declaración (Corte Interamericana de Derechos Humanos, 1989). ${ }^{.}$

\section{¿Podría Cuba regresar al sistema interamericano?}

La respuesta a la interrogante que da título a este epígrafe es que nunca se fue del todo. En efecto, más allá del discurso político que plantea que Cuba fue expulsada o desterrada de la OEA, lo cierto es que en el plano del Derecho Internacional no ocurrió nada semejante. Como ya hemos comentado, el gobierno cubano fue suspendido de la OEA en 1962. Sin embargo, ni Cuba denunció la Carta fundacional de esta organización, ni la OEA desarrolló otras acciones conducentes a lograr la total expulsión del país del sistema interamericano. De hecho, desde 1975, y en consonancia con el retorno gradual a la normalidad de las relaciones diplomáticas entre Cuba y la mayoría de las naciones latinoamericanas y caribeñas, la OEA comenzó a levantar algunas de las sanciones en contra de este país. Desde 2009, el Estado cubano ya no está suspendido de su participación en esta organización internacional. La vinculación jurídica de Cuba con la OPS y la CIDH-Comisión son otras dos muestras de que no se ha producido una desconexión total del Estado con el sistema interamericano.

Entonces, cabría preguntarse qué acciones puede desarrollar Cuba, sin renunciar a los principios fundamentales de su régimen socioeconómico y sociopolítico, para su reincorporación plena al sistema 
interamericano. Debemos precisar que nuestro análisis se centrará en las condiciones jurídicas que tanto en el Derecho interno como en el Derecho Interamericano, se aprecian como válidas y suficientes para lograr el regreso pleno del Estado cubano a la institucionalidad y el marco jurídico continentales. No hemos obviado que desde la discursiva de la dirigencia política cubana, tanto en los años setenta del siglo pasado como luego del 2009, se ha rechazado la posibilidad de que el país retome su participación en la OEA. El gobierno cubano expresó su desinterés por la reincorporación al organismo, sin dejar de distinguir como proeza la rebeldía latinoamericana en la Asamblea General que debatió en Honduras el retorno de Cuba a la institución (Castro, 2009).

Otra precisión importante es que en la resolución del 2009 se señaló que Cuba debería solicitar el inicio de un proceso de diálogo con la OEA y adherirse a las prácticas, los propósitos y los principios fundamentales relacionados con la seguridad, la democracia, la autodeterminación, la no intervención, los derechos humanos y el desarrollo. Una perspectiva sobre el vínculo del Estado cubano con tales prácticas, propósitos y principios puede obtenerse del análisis de la Consitución de 2019.

En esta carta magna se dedica un artículo a la definición de los principios que informan las relaciones exteriores de Cuba, y algunos de ellos se corresponden, a nuestro juicio, con la axiología de la Carta de la OEA y otros tratados regionales. Acorde con lo preceptuado en el artículo 16 constitucional, la República de Cuba basa las relaciones internacionales en el ejercicio de su soberanía y los principios antiimperialistas e internacionalistas, en función de los intereses del pueblo y, en consecuencia, se sistematizan un conjunto de reglas que sistematizan las características de la política exterior cubana. Así, sostiene su voluntad de observar de manera irrestricta los principios y normas que conforman el Derecho Internacional, en particular la igualdad de derechos, la integridad territorial, la independencia de los Estados, el no uso ni amenaza del uso de la fuerza en las relaciones internacionales, la cooperación internacional en beneficio e interés mutuo y equitativo, el arreglo pacífico de controversias sobre la base de la igualdad, el respeto y los demás principios proclamados en la Carta de las Naciones Unidas; y reafirma su voluntad de integración y colaboración con los países de América Latina y del Caribe (artículo 16 incisos c) y d), Constitución de la República de Cuba, 2019). La voluntad de Cuba de integrarse con los países de América Latina y el
Caribe tiene un antecedente constitucional directo en el artículo 12 inciso c) de la Constitución de 1976 (Constitución de la República de Cuba, 2003).

Del mismo modo, se indica que en sus relaciones internacionales Cuba defiende y protege el disfrute de los derechos humanos y repudia cualquier manifestación de racismo o discriminación; condena la intervención directa o indirecta en los asuntos internos o externos de cualquier Estado y, por tanto, la agresión armada, cualquier forma de coerción económica o política, los bloqueos unilaterales violatorios del Derecho Internacional, $u$ otro tipo de injerencia y amenaza a la integridad de los Estados; mantiene y fomenta relaciones de amistad con los países que, teniendo un régimen político, social y económico diferente, respetan su soberanía, observan las normas de convivencia entre los Estados y adoptan una actitud recíproca con nuestro país, de conformidad con los principios del Derecho Internacional; y promueve el multilateralismo y la multipolaridad en las relaciones internacionales, como alternativas a la dominación y al hegemonismo político, financiero y militar o cualquier otra manifestación que amenacen la paz, la independencia y la soberanía de los pueblos (Artículo 16 incisos g), h), ñ) y o), Constitución de la República de Cuba, 2019).

Estos contenidos constitucionales se ajustan con los dos pilares sobre los cuales descansa el sistema interamericano: la igualdad jurídica de los Estados y el principio de no intervención. El primero se traduce, entre otros aspectos, en que cada Estado tiene un voto en los órganos de representación gubernamental y que los mismos están abiertos a la participación de todos los Estados. El segundo, complemento directo del antes mencionado, es el instrumento que permite hacer realidad el principio de la igualdad jurídica de los Estados. Su límite es el que le fija la norma internacional común, la que excluye de la competencia nacional algún ámbito que queda entonces al margen de la posibilidad de invocarlo, como es el caso de la protección de los derechos humanos. A ellos se suman otros principios como el principio de la solución pacífica de las controversias y el respeto a los derechos fundamentales de la persona humana (Arrighi, 2009, pp. 72 y 73). Estos últimos también están positivados en la Constitución cubana de 2019, en el ya citado artículo 16 incisos c) y g), por ese orden.

De igual forma, resalta que en el artículo 45 de la nueva carta magna cubana se fijan como limitaciones al ejercicio de los derechos la vigencia y observancia de los derechos de los demás, la seguridad colectiva, 
el bienestar general, el respeto al orden público, a la Constitución y a las leyes (Constitución de la República de Cuba, 2019). Esto puede ser entendido a priori y sin dejar de valorar el resto de la sistemática constitucional, las demás normativas vigentes y la práctica política, signada por el no acatamiento de los parámetros interamericanos sobre derechos humanos, como un cambio favorable respecto a los estándares internacionales en esta temática, ya que una gran parte de los nuevos parámetros para las restricciones coincide con los mismos. Los artículos 13; 15 y 16 de la Convención Americana de Derechos Humanos, de la cual Cuba no es Estado Parte, y en los que se garantizan las libertades de expresión, información, reunión y asociación respectivamente, refrendan estos mismos parámetros para la definición de eventuales restricciones. Entre ellos están la previsión en ley y las finalidades legítimas de acuerdo con los criterios internacionales (respeto a los derechos y reputación de terceros, protección de la seguridad nacional, orden público, moral o salud pública), y la necesidad y proporcionalidad en el caso concreto (Carbonell et al., 2002, pp. 215 y 216).

Por tanto, es posible identificar cierto grado de vinculación entre las limitaciones pautadas para el ejercicio de los derechos constitucionales en el ordenamiento jurídico cubano, con las establecidas en el Derecho Interamericano, e inclusive en tratados internacionales firmados por Cuba en el marco del sistema universal, como es el caso del Pacto Internacional de Derechos Civiles y Políticos. Este último, firmado el 28 de febrero de 2008 pero no ratificado aún, no es vinculante para el Estado cubano. Empero, en la doctrina internacionalista nacional se aduce que la firma de un tratado tiene varias acepciones y consecuencias. Primero, sirve para autenticar el texto negociado y aprobado por los negociadores, aunque no significa que ya los obliga, salvo que de manera expresa así se disponga en el tratado. En segundo lugar, el período de tiempo que media entre la firma y ratificación de un tratado internacional puede emplearse para crear condiciones que aseguren el cumplimiento de las obligaciones que el Estado asumirá en sede del Derecho Internacional, una vez proceda con el acto formal de ratificación (Miranda, 2006, pp. 83 y 84). De igual manera, nos parece oportuno resaltar que la formulación de algunos derechos fundamentales recogidos en la Constitución de 2019 se aproxima más a la que tienen algunos de los que aparecen en instrumentos jurídicos internacionales, tanto del sistema interamericano como en el universal. Por lo tanto, puede afirmarse que hay un movimiento en la lex fundamental vigente a reconocer derechos con un contenido más cercano a los criterios internacionales.

Tomando en cuenta lo comentado hasta aquí, cabría preguntarse de qué forma podría efectuarse la reincorporación plena de Cuba al sistema interamericano. Para exponer nuestra postura sobre este particular, nos apoyaremos en las proposiciones de Ramacciotti sobre cómo lograr un regreso paulatino de este país al mencionado sistema. La autora conviene que podrían implementarse seis iniciativas: Mesa de Diálogo, Grupo de Trabajo OEA-Cuba, Reuniones de Ministros/OEA, Mecanismos de Seguimiento/OEA, Sociedad civil/OEA y Seminarios y conferencias/OEA (Ramacciotti, 2016, 350-352). A estos espacios podrían sumarse otros especializados sobre asuntos en los que puede verificarse mayor sinergia entre la OEA y Cuba. Lo anterior con el objetivo de ir elevando el nivel de confianza política entre ambos sujetos del Derecho Internacional. Así podrían crearse foros de negociación y concertación técnicos en temas puntuales y a la vez estratégicos de la agenda interamericana, como son enfrentamiento al cambio climático, mitigación de los efectos de desastres naturales, seguridad alimentaria, enfrentamiento a las drogas, entre otros.

\section{Conclusiones}

En este artículo hemos discurrido sobre el origen y actualidad del sistema interamericano y las relaciones de Cuba con este. Si bien es cierto que se trata de un país fundador del mismo y que en 1962 fue suspendido de la OEA, es innegable que existen vínculos jurídicos del Estado cubano con la estructura orgánica y con algunos de los tratados internacionales que conforman el sistema interamericano. La resolución que la Asamblea General de la OEA adoptó en 2009 dejando sin efecto la suspensión del gobierno cubano, constituyó, a nuestro juicio, un paso en la dirección correcta para lograr la plena incorporación de Cuba al mismo.

El hecho mismo de que en la citada resolución no se establezcan condicionamientos referidos a los principios sobre los cuales se sustenta el sistema político y/o el ordenamiento jurídico cubanos, sui géneris en la región, demuestra que es posible la incorporación del país a las instituciones interamericanas y al marco normativo del Derecho Interamericano. La necesidad de que el retorno pleno de Cuba a la OEA y demás organizaciones, entidades e instituciones regionales sea producto de un proceso de diálogo, sirve de referencia de uno de los caracteres que 
distinguen a estos sujetos del Derecho Internacional Público, a saber: la autonomía jurídica. Los mismos se caracterizan por poseer una personalidad jurídica independiente de la de sus miembros. Aunque su accionar se ve influido por la presencia en su seno de los Estados miembros, son capaces de elaborar y manifestar su voluntad autónoma en los ámbitos en los que gozan de competencia, de manera que, cualquiera que sea el órgano que adopte la decisión, esta se imputará a la organización y no a sus Estados miembros individual o colectivamente considerados (Diez de Velazco, 2002, p. 47).

Lo anterior explica, de conjunto con la coyuntura geopolítica regional en torno a Cuba, matizada por el diferendo de este país con Estados Unidos, acrecentado desde 1959, por qué la OEA adoptó una resolución revocando la suspensión del gobierno cubano en 2009, cuando la mayoría de los Estados que la integran comenzaron a restablecer relaciones con Cuba, desde mediados de la década del setenta del pasado siglo. A su vez, este orden de cosas evidencia que en el continente, y de manera gradual, se ha ido consolidando la idea de que dicho país puede y debe participar en el conglomerado de organizaciones, instituciones y entidades de alcance continental. Si en un momento particular la afiliación del Estado cubano al marxismo-leninismo y su promoción del socialismo y el comunismo fueron elementos que se creyeron suficientes para su expulsión de la OEA, en tanto se asumieron como contrarios al ideal de democracia de la región, hoy esa realidad ha cambiado. Valórese que cuando se adoptó la Resolución AG/ RES. Nº2438 (XXXIX-O/o9) en el año 2009, en Cuba se encontraba vigente la Consitución de 1976, reformada en 1978, 1992 y 2002. En ella se reconocía al marxismo-leninismo como ideología oficial del Estado cubano (Preámbulo y artículo 5 de la Constitución de la República de Cuba, 2003).

Asimismo, no existe contradicción entre el respaldo que en el articulado de la Carta de la OEA se le brinda a la democracia representativa y las características del sistema político cubano. En los hechos, la suspensión del Estado cubano en el sistema interamericano ocurrió durante el Período de Provisionalidad (Colectivo de Autores, 1982), es decir, en un momento en que la institucionalidad del país no estaba del todo definida, lo cual ocurriría con la entrada en vigor Constitución de 1976. Desde entonces, y teniendo en cuenta las reformas de la misma en 1978, 1992 y 2002, hasta la adopción del nuevo texto constitucional en 2019, el sistema político de Cuba siempre se ha vertebrado con base en la soberanía popular y la democracia representativa. El diseño constitucional del principio de soberanía popular y de la estructura estatal tiene entre sus componentes la existencia de instituciones representativas (artículos 3 y 68 inciso a) de la Constitución de la República de Cuba, 1976; y artículos 3 y 101 inciso a) de la Constitución de la República de Cuba, 2019).

La gran diferencia del sistema político cubano con respecto a los del continente, al menos en lo que a su estructura se refiere, es que se trata de un sistema monopartidista. Según Ramacciotti los Estados en el sistema interamericano tienen derecho a elegir, en ejercicio de su soberanía, las modalidades de democracia representativa que estimen convenientes. Esta es una de las razones por la que no aparece en la Carta Democrática, adoptada en 2001, una definición exacta de democracia. Sin embargo, se exige que el sistema político interno mantenga el núcleo duro de elementos democráticos: elecciones periódicas, libres, multipartidarias y justas basadas en el voto secreto y universal; régimen plural de partidos políticos; separación e independencia de poderes; y respeto a los derechos humanos y las libertades públicas (Ramacciotti, 2016, p. 349).

Sin embargo, Cuba tenía un sistema de partido único al momento de dejarse sin efecto la suspensión de su gobierno del sistema interamericano, característica que aún se mantiene en la Consitución vigente (artículo 5 de la Constitución de la República de Cuba, 1976; y artículo 5 de la Constitución de la República de Cuba, 2019). A esto debe sumarse que en el artículo 13 de la Carta de la OEA se recoge el derecho de los Estados miembros a defender su integridad e independencia, proveer a su conservación y prosperidad y, por consiguiente, de organizarse como mejor lo entendiere, legislar sobre sus intereses, administrar sus servicios y determinar la jurisdicción y competencia de sus tribunales. El ejercicio de estos derechos no tiene otros límites que el ejercicio de los derechos de otros Estados conforme al derecho internacional (Organización de Estados Americanos, 2020). Esta postura es consecuente con el criterio doctrinal que identifica en el artículo 2 de la Carta de la OEA, en el cual se alude al cumplimiento por parte de esta organización de las obligaciones regionales de acuerdo con la Carta de las Naciones Unidas, la reafirmación de ocho principios relativos a los derechos de los Estados. Como parte de los mismos incluye el derecho a la autonomía constituyente, que al mismo tiempo es una facultad derivada del derecho a la independencia, en virtud del cual destaca como un mínimum la facultad de 
elegir, con total libertad, la organización interna del Estado, política, económica y social, e instituir sus autoridades nacionales. La competencia constituyente es la mínima expresión del derecho de los Estados a la independencia (Halajczuk y Moya, 1999, pp. 190, 199 y 200).

Como complemento de lo anterior, en la propia Carta se reconocen entre los principios que rigen el actuar de los Estados miembros de la OEA, que el Derecho Internacional es norma de conducta de los Estados en sus relaciones recíprocas y que el orden internacional está constituido, en lo esencial, por el respeto a la personalidad, soberanía e independencia de los Estados y por el fiel cumplimiento de las obligaciones emanadas de los tratados y de otras fuentes del Derecho Internacional. Se añade que todo Estado tiene derecho a elegir, sin injerencias externas, su sistema político, económico y social, y a organizarse en la forma que más le convenga, y tiene el deber de no intervenir en los asuntos de otro Estado. Con sujeción a lo arriba dispuesto, los Estados americanos cooperarán ampliamente entre sí y con independencia de la naturaleza de sus sistemas políticos, económicos y sociales. También se preceptúa que cada Estado tiene el derecho a desenvolver libre y espontáneamente su vida cultural, política y económica. En este libre desenvolvimiento el Estado respetará los derechos de la persona humana y los principios de la moral universal (artículo 3 incisos a), b) y e) y artículo 17 de la Carta de la OEA, 2020).

De ahí que como parte de un futuro e hipotético proceso de diálogo entre Cuba y la OEA podrán discutirse matices, pero la mayor parte de los Estados americanos y la propia organización han asentido que corresponde al Estado cubano definir su propio sistema sociopolítico y socioeconómico. De tal manera, y aunque creemos que la plena reincorporación de Cuba a la OEA no debería implicar una reforma de su Carta constitutiva en todas aquéllas disposiciones sobre democracia representativa, ni la derogación de los instrumentos jurídicos prodemocráticos, ni obviar estas disposiciones fundamentales, somos del criterio que podría existir un proceso negociador que conllevara al regreso total del país al sistema interamericano, con base en la racionalidad y el pragmatismo políticos.

Para Cuba, reingresar a la OEA como miembro pleno significaría aumentar su visibilidad y prestigio en un mundo internacional competitivo, y a la vez, permitiría que los cubanos sean beneficiarios de la cooperación interamericana a través de la admisión como Estado miembro de varias organizaciones internacionales, verbigracia el BID. En el caso de esta última institución, se actuaría de acuerdo a lo dispuesto en el artículo II, sección 1 del Convenio Constitutivo del BID (Organización de Estados Americanos, 2020). Inclusive, y luego de concluido el proceso de diálogo entre dicha organización y el Estado cubano, podría valorarse por las autoridades de este último la ratificación del Pacto de San José y sus protocolos adicionales, así como con la aceptación de la competencia de la Corte Interamericana de Derechos Humanos. Esto posibilitaría el acceso a una nueva instancia de administración de justicia por parte de los ciudadanos cubanos, con base en los estándares regionales de derechos humanos, lo que repercutiría sobre la tutela judicial efectiva de estos. Todo ello implicaría adecuaciones importantes del ordenamiento jurídico nacional.

Desde la perspectiva de la OEA, se podría considerar un retorno paulatino del país al foro hemisférico a través de distintas iniciativas, en especial, la instalación de una Mesa de Diálogo, que puede promover y facilitar, paso a paso, el intercambio de puntos de vistas e iniciativas concretas que permitan avanzar hacia una plena reinserción cubana al foro hemisférico en el futuro. Todo esto sin que se produzcan interferencias con el normal funcionamiento de la organización ni debilitar los principios y las normas democráticas interamericanas (Ramacciotti, 2016, p. 353).

Del lado de Cuba quedaría admitir en sus relaciones con el sistema interamericano un conjunto de principios y prácticas en materia de derechos humanos, de los cuales, como ya se expuso, algunos coinciden con preceptos incorporados en el Derecho interno, al menos formalmente, luego de la reforma constitucional de 2019. Más allá de inconformidades sobre su funcionamiento, no caben dudas de que es uno de los más avanzados a nivel mundial en la promoción, tutela y defensa de los derechos humanos, cuestión esta que requiere de perfeccionamiento en el contexto nacional. El país nunca ha denunciado de forma expresa la Carta de la OEA, por lo que las obligaciones asumidas en virtud de este tratado se mantienen vigentes y, por tanto, son exigibles.

\section{Referencias}

Arrighi, J. (2009). El sistema interamericano y la defensa de la democracia, Revista Agenda Internacional, 27, pp. 69-94. 
Arrighi, J. (2015). La OEA y el Derecho Internacional. México D.F.: Porrúa.

Becerra, M. y Ávalos, R. (2020). Derecho de los Tratados. Teoría y práctica. México D.F.: Instituto de Investigaciones Jurídicas de la Universidad Autónoma de México.

Carbonell, M. et al. (comps.) (2002). Derecho Internacional de los Derechos Humanos. Textos Básicos. México D.F.: Porrúa.

Castro, F. (2009). “Caballo de Troya”. Recuperado de http://www.granma.cubaweb.cu/ secciones/ref-fidel/art15o.html.

Colectivo de Autores (1982). Discursos, artículos y otros documentos de Derecho Constitucional. Santiago de Cuba: Universidad de Oriente.

Comisión Interamericana de Derechos Humanos (2018). Informe Especial sobre la Situación de la Libertad de Expresión en Cuba. OEA/ SER.L/V/II. Washington D.C.: OEA.

Comisión Interamericana de Derechos Humanos (2020). Situación de los derechos humanos en Cuba. OEA/Ser.L/V/II.Doc.2. Washington D.C.: OEA.

Comisión Nacional de los Derechos Humanos (2018). Documentos Básicos en materia de Derechos Humanos en el Sistema Interamericano. México D.F.

Corte Interamericana de Derechos Humanos. Opinión Consultiva OC-10/89 del 14 de julio de 1989. Interpretación de la Declaración Americana de los Derechos y Deberes del Hombre en el marco del artículo 64 de la Convención Americana sobre Derechos Humanos, solicitada por el gobierno de la República de Colombia. Recuperado de http:// www.saij.gob.ar/corte-interamericanaderechos-humanos-internacional-sanjose-costa-rica-opinion-consultiva-oc10-89-14-julio-1989-serie-10-solicitanterepublica-colombia-fa89570000-1989-0714/123456789-0oo-0759-8ots-eupmocsollaf.

Cubadebate (2020). Cuba elegida por quinta ocasión como miembro del Consejo de Derechos Humanos de la ONU. Recuperado de http://www.cubadebate.cu/ noticias/2020/10/13/cuba-elegida-por-quintaocasión-como-miembro-del-consejo-dederechos-humanos-de-la-onu.
Cuevas, F. (1962). Tratado sobre la Organización Internacional. México D.F.: Jus S.A.

Departamento de Derecho Internacional de la Secretaría General de la OEA (2020). Fecha de ratificación o adhesión, y en su caso, denuncia, a los instrumentos interamericanos de derechos humanos. Recuperado de http://www.oas.org/es/sla/ddi/tratados_ multilaterales_interamericanos_A-41_carta_ OEA_firmas.asp.

Diario Granma (2017). Ingresa Cuba al Banco Centroamericano de Integración Económica. Recuperado de http://www.granma. $\mathrm{cu} / \mathrm{cuba} / 2017-08-28 /$ ingresa-cuba-albanco-centroamericano-de-integracióneconomica-28-08-2017-13-08-57.

Diez de Velazco, M. (2002). Las organizaciones internacionales. $12^{\mathrm{ma}}$ edición. Madrid: Tecnos.

Diez de Velazco, M. (2013). Instituciones de Derecho Internacional Público. $18^{\mathrm{ma}}$ edición. Madrid: Tecnos.

García, C. (1983). Derecho Internacional Público. México D.F.: Porrúa.

Guanche, J. (2015). Estado, participación y representación política en Cuba. Diseño institucional y práctica política tras la Reforma Constitucional de 1992. La Habana: Ciencias Sociales y Ruth Casa Editorial.

Halajczuk, B. y Moya, M, (1999). Derecho Internacional Público. $3^{\text {ra }}$ edición actualizada. Buenos Aires: EDIAR.

Herdegen, Matthias. Derecho Internacional Público. México D.F.: UNAM y Fundación Konrad Adenauer, 2015.

Gleijeses, P. (2004). Misiones en Conflicto. La Habana, Washington y África. 1959-1976. La Habana: Ciencias Sociales.

Ledesma, H. (2004). El sistema interamericano de protección de los derechos humanos: aspectos institucionales y procesales. San José de Costa Rica: Instituto Interamericano de Derechos Humanos.

LeoGrande, W. y Kornbluh, P. (2015). Diplomacia encubierta con Cuba. Historia de las negociaciones secretas entre Washington y La Habana. México D.F.: Fondo de Cultura Económica. 
Miranda, O. (2006). Derecho de Tratados. En Colectivo de Autores, Temas de Derecho Internacional Público (pp. 79-127). La Habana: Ed. Félix Varela.

O'Donnell, D. (1989). Protección Internacional de los derechos humanos. $2^{\mathrm{da}}$ edición. Lima: Comisión Andina de Juristas.

Organización de Estados Americanos (2020). Carta de la Organización de Estados Americanos. Recuperado de http://www. oas.org/es/sla/ddi/tratados_multilaterales_ interamericanos_A-41_carta_OEA.asp.

Organización de Estados Americanos (2020). Convenio Constitutivo del Banco Interamericano de Desarrollo. Recuperado de http://www.oas.org/dil/esp/tratados_C-15_ Convenio_constitutivo_del_Banco_ Interamericano_de_Desarrollo.htm.

Organización de Estados Americanos (2020). Tratado Interamericano de Asistencia Recíproca. Recuperado de http://www.oas. org/juridico/spanish/tratados/b-29.html.

Pelayo, C. (2011). Introducción al Sistema Interamericano de Derechos Humanos. México D.F.: Comisión Nacional de los Derechos Humanos.

Pisani, M. (1985). Fundamentos de Derecho Internacional Público. Tomo I. La Habana: Universidad de La Habana.

Preciado, J. y González, P. (2011). Cuba en el nuevo sistema interamericano del siglo XXI. En Ayerbe, L. (coord.), Cuba, Estado Unidos y América Latina frente a los desafíos hemisféricos (pp. 47-68). Madrid: Icaria.

Quintana, D. (2006). La protección internacional de los derechos humanos. En Colectivo de Autores, Temas de Derecho Internacional Público (pp. 142-153). La Habana: Ed. Félix Varela: 2006.

Ramacciotti, B. (2016). Cuba y el Sistema Interamericano: ¿Hacia una integración progresiva y funcional en la OEA?". Anuario de Integración, edición especial, pp. 335-366.

Sepúlveda, C. (1974). El Sistema Interamericano. Génesis, integración y decadencia. México D.F.: Porrúa.

Sierra, M. (1955). Tratado de Derecho Internacional Público. México D.F.: Porrúa.
Toro, L. (2019). La Denuncia y el Retiro de los Tratados en el Sistema Interamericano. En Comité Jurídico Interamericano, Curso de Derecho Internacional Público (pp. 79-116). Washington D.C.: OEA.

Unión Panamericana (1956). Convenciones en Conferencias Interamericanas, Segundo Suplemento, 1945-1954. Washington D.C.: OEA.

\section{Legislación}

Cuba, Asamblea Nacional del Poder Popular, Constitución de la República de Cuba de 24 de febrero de 1976, reformada en 1978, 1992 y 2002. Gaceta Oficial Ordinaria $N^{\circ} 3$, de 31 de enero de 2003.

Cuba, Asamblea Nacional del Poder Popular, Constitución de la República de Cuba de 24 de febrero de 2019. Gaceta Oficial Extraordinaria $N^{\circ} 5$, de 10 de abril de 2019 .

\section{Notas}

1 Al momento de redactarse este trabajo, se encuentra en tramitación ante la CIDH-Corte una solicitud de opinión consultiva presentada por la República de Colombia, relativa a las obligaciones sobre derechos humanos de un Estado que denuncie la Convención Americana sobre Derechos Humanos e intente retirarse de la OEA. Dicha solicitud está disponible en: http://www.corteidh. or.cr/docs/opiniones/sol_oc_26_esp.pdf. 